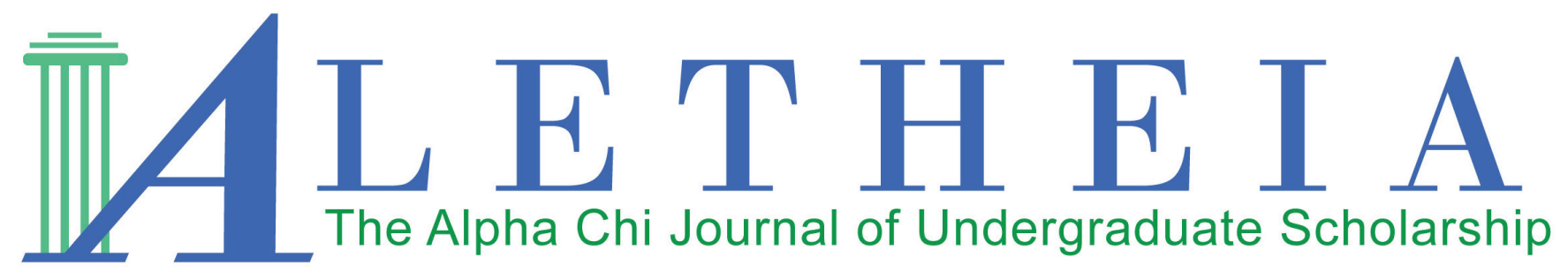

Volume 1 | Issue 2 | 2016

\title{
The Prevalence of Self-Perceived Stress and Depression in Undergraduate NCAA Student Athletes and Student Non-Athletes
}

\author{
Samantha Bureau \\ Franklin Pierce University \\ New Hampshire Zeta
}

Vol. 1(2), 2016

Article Title: The Prevalence of Self-Perceived Stress and Depression in Undergraduate NCAA Student Athletes and Student Non-Athletes

DOI: $10.21081 / \mathrm{ax} 0073$

ISSN: $2381-800 \mathrm{X}$

Key Words: NCAA athletes, stress, depression, elite athletes, athletics, mental well-being This work is licensed under a Creative Commons Attribution 4.0 International License.

Author contact information is available from the Editor at editor@alphachihonor.org.

\section{Aletheia-The Alpha Chi Journal of Undergraduate Scholarship}

- This publication is an online, peer-reviewed, interdisciplinary undergraduate journal, whose mission is to promote high quality research and scholarship among undergraduates by showcasing exemplary work.

- Submissions can be in any basic or applied field of study, including the physical and life sciences, the social sciences, the humanities, education, engineering, and the arts.

- Publication in Aletheia will recognize students who excel academically and foster mentor/mentee relationships between faculty and students.

- In keeping with the strong tradition of student involvement in all levels of Alpha Chi, the journal will also provide a forum for students to become actively involved in the writing, peer review, and publication process.

- More information and instructions for authors is available under the publications tab at www.AlphaChiHonor.org. Questions to the editor may be directed to editor@alphachihonor.org.

\footnotetext{
Alpha Chi is a national college honor society that admits students from all academic disciplines, with membership limited to the top 10 percent of an institution's juniors, seniors, and graduate students. Invitation to membership comes only through an institutional chapter. A college seeking a chapter must grant baccalaureate degrees and be regionally accredited. Some 300 chapters, located in almost every state, induct approximately 12,000 members annually. Alpha Chi members have been "making scholarship effective for good" since 1922.
} 
Article Title: The Prevalence of Self-Perceived Stress and Depression in Undergraduate NCAA Student Athletes and Student Non-Athletes

DOI: $10.21081 / \mathrm{ax} 0073$

ISSN: 2381-800X

This work is licensed under a Creative Commons Attribution 4.0 International License.

\title{
The Prevalence of Self-Perceived Stress and Depression in Undergraduate NCAA Student Athletes and Student Non-Athletes
}

\author{
Samantha Bureau \\ Franklin Pierce University \\ New Hampshire Zeta
}

\begin{abstract}
Previous research has explored the pressures of an elite athlete (any athlete at or above the Division I collegiate level) and the correlation between these stressors and athletic participation; however, relatively little research has been done regarding the prevalence of depression and stress among these athletes in comparison to non-athletes (Armstrong \& Oomen-Early, 2009). This study aims to explore the prevalence of stress and depression of undergraduates as it relates to athletic status and gender. This study also aims to explore the relationship between the dependent variables and hours spent on extracurricular activities. Participants $(n=113)$ were selected on a volunteer basis from a Private Liberal Arts College in the Northeastern United States. Participants were asked to complete an online survey consisting of demographic questions, the Center for Epidemiologic Studies Depression Scale-Revised (CESD-R), and the Perceived Stress Scale (PSS). No significant results for stress and depression were found based on athletic status and there was no significant interaction effect between gender and athletic status variables. On the whole, the mean stress score for females $(M=18.86, S D=6.46)$ was higher than for males $(M=15.75, S D=6.36), p=0.016$; however, no significant results were found for depression based on gender after further analysis. Furthermore, 32.7\% of the sample reported clinical levels of depression and there was a statistically significant relationship between stress and depression. These findings were partially supported by previous research.
\end{abstract}

Key words: NCAA athletes, stress, depression, elite athletes, athletics, mental well-being

For the purposes of this study, elite athletes are defined as any athlete participating in a level of athletics at or above the collegiate (NCAA) level. All athletes at this level, regardless of playing time, are considered elite in nature because the demands, with the exception of playing time during competitions, of each athlete remain the same. In season, NCAA athletes are allowed to participate in up to 20 hours of athletic-related activities, which does not always include travel time as games/competitions are counted as 3 hours regardless of actual length and travel time. Elite athletes (professional, collegiate, Olympic, etc.) must dedicate much more time and make considerably more sacrifices to athletics than the traditional recreational athlete that spends much less time on athletics on a weekly basis. This is true because while recreational athletes participate purely for their own pleasure and benefit, elite athletes must meet and put first the demands of their coaching staff and others in the athletic organization. As a result, elite athletes are under a much higher level of pressure to succeed, and to win (Goodman, Kashdan, Mallard, \& Schumann, 2014). With this increased commitment and increased pressure, it is questionable whether or not this level of athletics is as beneficial for overall well-being 
as recreational activities. The purpose of this research is to further understand the mental well-being of student athletes when compared to their non-athlete peers.

Mental health among university students is by no means a new topic. However, recent media exposure and mental health movements have given rise to an increase in the research and attention given to mental health among university students, and university athletes in particular. To date, a variety of research has explored the intense pressures of an elite athlete (athletes at or above the collegiate Division I level) and the correlation between these stressors and athletic participation; however, relatively little research has been done regarding the prevalence of depression and stress among these athletes in comparison to non-athletes (Armstrong \& Oomen-Early, 2009). Exercise is more often than not identified as an activity to decrease stress and increase overall well-being (Johnson \& Taliaferro, 2011); however, it is unclear whether or not this is true for all levels of athletics.

\section{Stress}

Stressors have been used to help identify which life events cause both positive and negative reactions. Malinauskas (2010) notes stress as a changing variable dependent on how an individual perceives and reacts to his or her situation. Stress can be sub-classified into the following two categories: eustress and distress, and when stress falls into the latter category it could be harmful to overall mental health (Lu, Hsu, Chan, Cheen, $\&$ Kao, 2012). For the purposes of this study, eustress is defined as any source of positive stress, while distress is defined as any source of negative stress. According to Gerber et al. (2013), stress has been cited as a contributing factor for increased maladjustment during teenage and young adult years. While stressors may arise in daily life through a variety of forms, recent studies have shown that when analyzing stress among a university population, it is helpful to distinguish between regular life stressors and academic stressors (Lester, 2014).

\section{Depression}

Depression has been noted in many studies as an issue on the rise, particularly for adolescents and young adults (Beiter et al., 2015; Brandy, Penckofer, Solari-Twadell, \& Velsor-Friedrich, 2015; Dishman et al., 2006; Ed- man, Lynch, \& Yates, 2014; Johnson \& Taliaferro, 2011; Merrill, Reid, Carey, \& Carey, 2014). Appaneal, Levine, Perna, and Roh (2009) have described depression in two different manners: a way to reflect negative affect (depressed feeling/mood), and a way to reflect psychiatric disturbance (major depression). Distinguishing between the two is important when attempting to understand the severity of the disturbance in an individual. Depressed mood is more accurately characterized as feeling down, while major depression is a clinical disorder with much more severe symptoms. As the prevalence of stress and depression gains attention, it is valuable to understand the negative effects that come along with these experiences, and more importantly, how these experiences manifest within the individual.

\section{Stress and Depression in Undergraduates}

Stress and depression are among many psychological experiences that affect students in higher education, particularly as they begin to make the transition from high school to university (Beiter et al., 2015). Furthermore, the prevalence of these experiences has risen in recent years, with a $92 \%$ increase in students seeking mental health assistance (Brandy et al., 2015). A recent study has shown that about $70 \%$ of adults in the United States reported experiencing at least moderate stress and/or anxiety daily, and about $10 \%$ of students in higher education have been diagnosed and/or treated for depression in the 12 months preceding the study (Beiter et al., 2015). Finally, a 2012 report released by the Association for University and College Counselling Center Directors indicates that an overwhelming number (95\%) of directors believe that psychological issues are a growing concern, with depression as one of the most prevalent concerns (Merrill et al., 2014).

It is important to recognize what aspects of life may play a role in the increasing prevalence of depression, anxiety, and stress. Academic excellence has continued to represent a major source of stress among students, particularly in higher education. Beiter et al. (2015) believe that academics are of major importance for college students and can cause increased distress if the student cannot handle the demands and increased academic rigour. Furthermore, a wide variety of negative health behaviours, which can be defined as any activity that contributes negatively to overall mental and/or physical well-being, have been associated with stress and depres- 
sion and often arise as a means of coping. Among these activities are alcohol and drug use and abuse, (Goodman et al., 2014; Storch, Storch, Killiany, \& Roberti, 2005) and eating disorders (Bravata, Storch, \& Storch, 2003; Storch et al., 2005). According to Merrill et al. (2014), previous research has identified a significant relationship between depression (subclinical and clinical) and substance abuse (namely alcohol).

\section{Stress and Depression in Athletes (Recreational and Elite)}

While these mental health concerns are widely generalizable to the university student population, the question is still whether or not these trends apply to student athletes in the same way they apply to non-athletes. Research on this matter has been divided across two contradicting views: one that believes student athletes experience lower levels of stress and depression and another that believes that student athletes experience higher levels of stress and depression. This contradiction in the literature has been acknowledged by Jones, Butryn, Furst, and Semerjian, (2014), Storch et al., (2005), and Wyshak, (2001). The discrepancy in the literature arises for a variety of different reasons, including different samples of the population, different scales used to quantify variables, or even different operational definitions of the variables, which contribute to the complexity of the issue. Unlike many traditional health issues, the onset of stress and depression cannot be attributed to specific triggers that are universal to everyone. Factors such as finances, satisfaction in life, self-esteem, sleeping habits, social relationships, and academics (Beiter et al., 2015) are all linked to the onset of stress and depression; however, none of these factors affects all individuals in the same way. Moreover, major gaps in the literature concerning this issue in relation to intercollegiate athletes identify mental health in university athletes as an understudied health issue (Armstrong \& Oomen-Early, 2009).

A considerable amount of the literature posits that exercise is beneficial for overall mental health and may act as a buffer against the onset of mental health disorders (Dishman et al., 2006; Edman et al., 2014; Jones et al., 2014; Kimball \& Freysinger, 2003; Miller \& Hoffman, 2009; Storch et al., 2005). Exercise has been negatively correlated to the onset of stress and depression (Dishman et al., 2006), and research has demonstrated that relatively low levels of exercise may protect against depression (Edman, et al., 2014). Ghaedi and Kosnin (2014) found that athletes demonstrate greater self-esteem and lower levels of depression than non-athletes. This claim is supported by the positive association hypothesis, which posits that participation in recreational sports is associated with positive changes in physical and mental health (Lodis, Sigmon, Martinson, Craner, McGillicuddy, \& Hale, 2012). Further, Miller and Hoffman (2009) found participants of one study on one or two high school teams had significantly better mental health than those not participating on any teams. However, there is no clear evidence that all levels of exercise provide positive mental health consequences. In the same study, Miller and Hoffman (2009) found that high school students who participated in three or more athletic teams did not demonstrate any significant mental health benefits.

Some studies suggest that exercise can foster negative body attitudes, which can be further related to depression (Edman et al., 2014). Furthermore, although research outlines the benefits of exercise, it doesn't take into account how the competition and pressures that come with collegiate athletics could negatively impact overall mental well-being. According to Brewer (1993), individuals who define their self-worth primarily on the basis of their performance of a single social role are vulnerable to depression following the occurrence of life events that threaten the individuals' performance of the self-defining role. These life events could include anything from injury to retirement, or even poor performance. Cremades and Wiggins (2008) found that the high expectations that come with higher-level athletics increases the amount of stress an athlete experiences. Finally, Lodis et al. (2012) found that many researchers believe that the poor mental health outcomes arising from collegiate athletics are due to the decreased social interactions resulting from the dual demands of academics and athletics. Some studies even suggest that athletics is not the root cause of stress in student athletes; rather, the time constraints experienced by this population are the root of the negative mental responses. Wilson and Pritchard (2005) reported most respondents in the study felt that there was not enough time to combine academics and athletics and perform optimally in both. Ultimately, the main question for the purposes of this research concerning exercise and mental health asks at what level of participation, if any, is athletics no longer beneficial from a mental health standpoint? 


\section{Stress and Depression Based on Gender}

When researching mental health in any population, it is important to consider gender differences. According to Nolen-Hoeksema (2001), females across many different cultures have demonstrated a greater susceptibility for depression than their male counterparts. Females have been identified as having two times the risk of developing depression or subclinical depressive symptoms than males (Altemus, 2006; Hankin, et al., 1998; Nolen-Hoeksema, 2001). Research has found that when males and females experience similar, if not the same stressors, females are more likely than males to have difficulties coping. Nolen-Hoeksema (2001) believed that this variance has been observed because of gender differences in biological responses to stress, coping mechanisms, and self-concepts. One interesting difference that has been noted by many researchers is females' greater tendency to respond to stressful situations with rumination (focusing inward on feelings as opposed to taking actions to relieve distress) than males (Altemus, 2006; Nolen-Hoeksema, 2001). On the whole, individuals who ruminate in response to stress are at greater risk of developing poor mental health experiences than those who do not (Nolen-Hoeksema, 2001).

A large body of research to date has attempted to understand why these differences occur, with little success (Hankin \& Abramson, 2001). According to Altemus (2006), although biological mechanisms seem to be the most logical reason for this difference, identifying a single mechanism responsible for this change has not yet occurred. This is partially due to conflicting animal and human models. Animal models have suggested that females are relatively resistant to neurological and behavioral effects of acute and chronic stress, but this has not been mirrored in human populations. Many other models have attempted to narrow this difference down to one unique factor; however, as more research has been conducted, it has become clear that integrated models are needed to understand these differences (Nolen-Hoeksema, 2001). While the reasons why this difference occur have yet to be determined, the fact that this difference has been observed widely in past research on mental health is particularly relevant to the current research.

\section{Stress and Depression in Elite Athletes}

As the field of sports-related psychiatry grows, an increasing amount of attention has been paid to the mental and emotional well-being of elite athletes. According to Schaal et al. (2011), recreational sport has been found to be an effective method to cope with stress and prevent psychological disorders; however, practicing at an elite level has been associated with entirely different outcomes. As mentioned earlier, this may be due to the fact that it is not necessarily the exercise that affects individuals negatively, but instead the increased pressures that come with athletics as they become increasingly more competitive. This would explain why recreational athletes reap the benefits of athletics, but elite athletes, at times, may not. Moreover, Schaal et al. (2011) stated that athletes not only heavily invest mentally in their sport, but they also experience incredible pressure to succeed.

Researchers have found relationships between elite level athletic participation and psychological issues such as depression and anxiety (Schaal et al., 2011). With this being said, the lack of knowledge of the complexity of an athlete has led to false diagnoses. According to Glick, Stillman, Reardon, and Ritvo (2012), sports physicians considered athletes experiencing fatigue, lack of motivation, irritability, and trouble sleeping as suffering from overtraining, while they labeled a non-athlete experiencing these symptoms with a more severe diagnosis. Overtraining has been cited as one of the main factors associated with subpar overall mental well-being in athletes (Miller \& Hoffman, 2009) and occurs when the athlete feels he or she has been overworked. Non-athletes may also experience this phenomenon in a similar way, but in other areas of their lives. It is important to be able to distinguish between the symptoms of overtraining and more serious health-related issues. Extensive overtraining can lead to burnout, which is why Cremades and Wiggins (2008) include similar, if not identical symptoms to overtraining when discussing burnout.

Student athletes are one subgroup of elite athletes that deserve particular attention in terms of mental well-being. Goodman et al. (2014) identified student athletes as a group at risk for emotional and behavioural difficulties. This is because student athletes not only bear the responsibilities of a regular student, but also the responsibilities and demands of an elite athlete. Once again, these athletes are considered elite in nature be- 
cause of the relatively small percentage of high school athletes that go on to this level or higher. According to the NCAA (2015), of the 8 million high school students participating annually in sports, only about 460,000 go on to the collegiate level and few from each sport then go on to the professional or Olympic level. Demands experienced by student athletes include but are not limited to "repetitive and exhausting training, frequent travels and competitions, injuries, pressures to win and avoid losses, internal competitions between teammates, media pressures, and sometimes burnout" (Lu et al., 2012, p. 254). An inability to cope with a build up of these stresses can lead to negative mental responses. Student athletes are expected to time manage around practice, competition, class, and other academic and athletic responsibilities, meet the expectations of those around them (coaches, professors, etc.), negotiate relationships, adjust to missing out on "regular college activities," deal with performance anxiety, and prepare for retirement from sports and graduation (Jones et al., 2014). Student athletes have also been identified as a subset of the population at a higher risk for developing eating disorders (Bravata et al., 2003; Storch et al., 2005; Wilkins, Boland \& Albinson, 1991) and alcohol disorders (Goodman et al., 2014). However, it is important to note that these are extreme experiences and are by no means experienced by all student athletes.

Another major source of stress and depression for student athletes is injury. In order to best understand the mental well-being of this subset of the population, it is important to consider all stressors that could contribute negatively to these individuals. While individuals of all subsets of the population sustain injuries regularly, relatively few of these injuries are serious or complicated from a medical standpoint. However, for individuals who find self-worth solely from their identity as an athlete, any injury inhibiting participation increases the risk for depression (Brewer, 1993; Petrie, Deiters, \& Harmison, 2014).

Finally, the literature also suggests that female student athletes are at a higher risk for developing depression than their male counterparts (Ghaedi \& Kosnin 2014; Jones et al., 2014). This supports the literature citing gender differences in the general population in relation to these variables. In support of this, Brown and Blanton (as cited in Miller \& Hoffman, 2009) noted that college females who participated in vigorous physical activity on a daily basis had significantly poorer health outcomes than their less active peers. Once again, this gender difference may be attributed to a variety of biological and psychological factors. As a result, it is important to recognize these differences in this particular subset of the student-athlete population and adjust coaching strategies and expectations accordingly.

\section{Current Research}

This study aims to explore the prevalence of stress and depression on a university campus as it relates to athletic status and gender. In addition, this study aims to explore the relationship between hours spent on extracurricular activities, and both stress and depression, independently. It was hypothesized that student athletes would exhibit a greater prevalence of perceived stress and depression when compared to student non-athletes. Furthermore, it was hypothesized that regardless of athletic status, females would exhibit a greater prevalence of perceived stress and depression when compared to males.

\section{Method}

\section{Participants}

Participants $(n=113)$ were selected on a volunteer basis from a Private Liberal Arts College in the Northeastern United States. Participants consisted of males ( $n$ $=28)$ and females $(n=71)$, as well as those who declined to reveal their gender $(n=14)$. Participants were considered either of NCAA athlete $(n=62)$ or non-athlete status $(n=49)$. It is important to note that club sport athletes were treated as non-athletes. All participants were undergraduate students, with ages ranging from 18 to 22 and a mean age of 19.65. Participants were of a diverse academic background, representing 18 different majors, and the majority of the students $(n=102)$ were taking a full course load (15+ credits), with an average of 15.33 credits taken per semester. The racial/ethnic composition of the sample was unknown, but was presumed to have consisted primarily of Caucasian participants based on the racial/ethnic composition of the institution. All identities were kept anonymous and participants were treated in accordance with the APA ethical guidelines. 


\section{Materials}

Three independent surveys, a demographic survey, the Center for Epidemiologic Studies Depression Scale-Revised (CESD-R), and the Perceived Stress Scale (PSS) were used to collect demographic data and quantify levels of depression and stress. All surveys were compiled into one computer-based survey that could be accessed both remotely and in the lab through SurveyMonkey.

The demographic survey consisted of 13 questions that would provide further data to analyze upon completion of the subsequent surveys. Questions regarding age, gender, grade level, major, number of credits, number of hours spent participating in extracurricular activities, athletic status (NCAA athlete or non-athlete), and injury status were asked in attempt to better understand the participant pool. Further, exploratory self-report questions regarding the opinion of how athletic participation and injury status affects mental well-being were asked of participants with a Likert-Scale for the purpose of collecting preliminary data for future study.

The CESD-R is a self-report scale that is used to quantify levels of depression in respondents (Eaton, Smith, Ybarra, Muntaner, \& Tien, 2004). The CESD-R consists of 20 questions that reflect the feelings of the individual in the past two weeks. The CESD-R is scored on a total scale of $0-80$, with each question scored on a scale of 0-4 (0 indicating not at all or less than one day and 4 indicating nearly every day for two weeks). Questions were created to test for nine separate common symptoms of depression: sadness, loss of interest, appetite, sleep, thinking/concentration, guilt, tired (fatigue), movement, and suicidal ideation. Scores of or over 16 indicate the presence of depression and can be further correlated to specific symptoms based on responses. While a score of 16 does not necessarily indicate the presence of major depression, this score suggests the individual should actively seek a professional's advice and/or help managing these symptoms ("CESD-R Explanation," n. d.). According to Radloff (1991), this scale has been validated with college students and has demonstrated a good internal consistency $(\boldsymbol{\alpha}=.84-.90)$.

The PSS is a self-report scale that is used to quantify levels of stress in respondents (Cohen, Karmarck, \& Mermelstein, 1983). The PSS is an inventory that consists of ten questions and is scored on a total scale of $0-40$, with each question being scored on a scale of $0-4$
(0 indicating never, and 4 indicating very often). Scores for questions $4,5,7$, and 8 are reversed, and all ten questions are summed to generate the final score. Scores ranging from 0-13 indicate low perceived stress, while scores ranging from 14-26 are considered moderate and scores ranging from 27-40 are considered high. The PSS has demonstrated good internal reliability $(\alpha=.84-.86$, Cohen et al., 1983) and "adequate validity correlating (r $=.62$ ) with the Daily Stress Inventory" (Lavoie \& Douglass, 2012, p. 51). Furthermore, the PSS has been tested for reliability across gender and was found to "[present] evidence that underlying constructs of the PSS are interpreted and measured the same way across gender" (Lavoie \& Douglas, 2012, p. 57).

\section{Procedure}

Participants $(n=113)$ were brought into a study room at the university $(n=55)$ on a volunteer basis or provided with a link to complete the study remotely ( $n$ $=58$ ). Participants were required to be 18 years or older to give consent. No other demographic restrictions were placed on participants. Participants were prompted to complete the demographic questionnaire, the CESD-R, and the PSS in the respective order, in an honest manner, to the best of their abilities. The survey administered remotely was identical to the survey administered to participants who completed the study in the lab. In order to preserve reliability, answers to specific questions that were reverse scored and completion times were used to eliminate any perceived unreliable data. Two sets of two nearly identical questions, one scored normally, the other reverse scored, were analyzed for consistency in answering pattern. Surveys of participants who did not answer reversed scored items consistently in regards to answer pattern (i.e. "Always" for the normal and "Always" for the reverse scored item as opposed to "Always" for the normal and "Never" for the reverse scored item) and/or completed the survey in under 10 minutes were discarded and removed from the final analysis. Of the total sample size, 95 were used for a two-way MANOVA. Exclusion of data for this test was either due to incomplete data $(n=15)$ or reliability reasons as mentioned previously $(n=3)$. Furthermore, no rewards were given to participants for their participation. 


\section{Results}

A two way MANOVA was used to test the hypotheses that athletes would experience higher levels of stress and depression when compared to non-athletes and that females would experience greater levels of stress and depression than males, as well as test for a potential interaction effect between the two independent variables. There was not a statistically significant interaction effect $F(2,93)=4.94, p=.612$, Wilk's $\Lambda=.989$. As depicted in Figure 1, the mean stress $(M=18.29, S D=$ $6.58)$ and depression $(M=13.61, S D=9.58)$ scores for female athletes were calculated, as were those of female non-athletes (stress: $M=20.31, S D=5.20$, depression: $M=15.41, S D=9.97$ ), male athletes (stress: $M=14.94$, $S D=6.05$, depression: $M=11.00, S D=11.67)$ and male non-athletes (stress: $M=16.83, S D=6.87$, depression: $M=16.33, S D=13.44)$.

There was a statistically significant main effect for gender $F(2,93)=4.23, p=.018$, Wilk's $\Lambda=.917$. However, after completing further statistical analysis, the difference in stress scores were significant $F(1,94)=6.022$, $p=.016$, while the difference in depression scores were not $F(1,94)=.125, p=.724)$. The mean stress $(M=$ $15.75, S D=6.36)$ scores for males were lower than those for females $(M=19.13, S D=6.09)$. There was no statistical difference between depression scores for males $(M=13.29, S D=12.51)$ and females $(M=14.36$, $S D=9.72)($ see Figure 1$)$.

There was not a statistically significant main effect for athletic status $F(2,93)=1.27, p=.285$, Wilk's $1=$ .973 . The mean stress $(M=17.35, S D=6.56)$ and depression scores $(M=12.88, S D=10.17)$ for athletes were calculated as were the stress $(M=19.29, S D=$ $5.87)$ and depression scores $(M=15.68, S D=10.93)$ for non-athletes (Figure 1).

Secondary analyses of the data were done to explore other relationships between the variables. Stress and depression were found to be positively correlated $(r(109)$ $=.647, p=.000)$, whereas no statistically significant correlation was found between extracurricular activities and stress $(r(108)=-.042, \mathrm{p}=.665)$ or depression $(r(108)=.039, p=.685)$.

Finally, all participants with depression scores at or above 16 (indicating clinical level of depression) were pulled to perform an ANOVA to test for differences based on athletic status and gender, as well as an interaction effect. Of the initial sample $(n=113), 32.7 \%$ of participants reported clinical levels of depression $(n=$ 37 ) as assessed based on the CESD-R guidelines. Scores of these participants ranged from 17-49 $(M=25.65$, $S D=9.20$ ). However, there was no statistically significant interaction effect ( $p=.368)$, main effect for gender $(p=.306)$, or main effect for athletic status $(p=.393)$.

\section{Discussion}

The purpose of this study was to explore the prevalence of stress and depression as it pertains to athletic status and gender. The hypothesis stating that athletes would experience greater levels of stress and depression than non-athletes was not supported by the data. Statistically, there was no significant difference between the two groups. This is not consistent with previous studies, which generally state that one of these groups generally shows higher levels of both stress and depression than the other. Research on this topic is conflicting and generally separated into two groups: one that states athletes experience lower levels of stress and depression than non-athletes (Dishman et al., 2006; Edman et al., 2014; Jones et al., 2014; Kimball \& Freysinger, 2003; Miller \& Hoffman, 2009; Storch et al., 2005), and a second that states athletes experience higher levels of stress and depression than non-athletes (Brewer, 1993; Cremades \& Wiggins; 2008, Edman et al., 2014; Lodis et al., 2012; Wilson \& Pritchard, 2005). One study in particular demonstrated conflicting results with regard to athletic participation and mental health. Miller and Hoffman (2009) found that participants of one study on one or two high school teams were significantly less likely to attempt suicide than non-participants. In this same study, the researchers found that high school students who participated in three or more athletic teams did not demonstrate any significant mental health benefits. With these two different views in mind, it is particularly important to continue researching the topic for potential breakthroughs.

The hypothesis stating that females would experience greater levels of stress and depression than males was partially supported by the data. Females showed significantly higher levels of stress than males, but there was no significant difference between the depression scores of these two groups. This is partially consistent with previous studies that have shown females to have a higher prevalence of stress and depression than their male counterparts (Altemus, 2006; Hankin et al., 1998; 
Hankin \& Abramson 2001; Ghaedi \& Kosnin 2014; Jones et al., 2014; Nolen-Hoeksema, 2001; Miller \& Hoffman, 2009). Altemus (2006) and Nolen-Hoeksema (2001) both discussed rumination as an inherent gender difference between females and males that may contribute to differences in mental health across gender. Females have a greater tendency to ruminate than males, which has been associated with poorer mental health outcomes. Moreover, this overall gender difference in regards to depression and other mental health aspects has been recognized cross-culturally (Altemus 2006; Nolen-Hoeksema, 2001), further supporting the current findings partially.

On the whole, this research is important because it provides valuable insight into the mental well-being of university students based on their athletic status and gender. With millions of individuals pursuing higher education each year, and hundreds of thousands of these individuals participating in NCAA sports, it is extremely important to understand the implications of these activities. Mental health has become an increasingly talked about issue in society, so in an attempt to fight the stigma, it is important to both understand and discuss the issue with populations at risk. According to Beiter et al. (2015), university students in general are a population at risk of developing depression and experiencing stress.

Despite the value gained, this research was not without limitations. First, while the sample was fairly diverse in age, academic major, and class level, the sample is not necessarily representative of student athletes and non-athletes at other universities across the country. The total population of the students at the institution studied is relatively homogenous, so these results are not necessarily generalizable. Second, the institution studied is of Division II NCAA status, so these results may not be mirrored at Division I or Division III institutions. Since the commitment required of athletes at a Division I institution is greater than at both Division II and Division III institutions, it is possible that these athletes would demonstrate statistically significant levels of stress and depression compared to non-athletes. Third, the overall campus size is very small, with a low teacher to student ratio, when compared to universities across the country. This could have had an effect on the results of the study because students may have felt that they had many resources available to them, helping them control their stressors. Furthermore, student athletes may benefit from small class sizes and good relationships with pro- fessors by being able to miss classes for sporting events without many academic penalties, eliminating a source of stress. Finally, this study analyzed a sample with a considerably lop-sided gender pool (males $=28$, females $=71$, decline to answer $=14$ ). Because of this, the results based on gender should be acknowledged with the understanding of this limitation. Further and more extensive research is needed to confirm this finding.

In terms of methodology and control, two very different testing settings were used to accommodate participants. About half of the participants participated in a controlled setting (study room), while the other half of the participants were free to take the survey whenever and wherever was convenient for them. This may have affected the accuracy of the results. Next, all measures were self-report, which introduces limitations regarding the validity of the response. Considering the sensitivity of the subject matter, it is possible that individuals did not respond honestly. However, with this in mind, the online method of distribution ensured anonymity of the participant to even the researcher, which may have increased honesty while reporting answers.

Future research should build on these results to further explore the causes of stress and depression in this population. Researchers should test athletes and non-athletes at a variety of institutions (different geographic regions, different institution sizes, etc.) to compare the trends in the data and make the results more generalizable. Researchers could also test for differences in stress and depression among student athletes in regards to their division (I, II, or III). Additionally, researchers should attempt to separate the effects of exercise and the effects of competition in regards to perceived stress and depression. If these factors can be tested separately, researchers may be able to provide reasoning for the conflicting views on the topic to date. Finally, when conducting future research, it may be beneficial to test for physiological symptoms of stress and depression as well as using self-report questionnaires. 


\section{References}

Altemus, M. (2006). Sex differences in depression and anxiety disorders: Potential biological determinants. Hormones and Behavior, 50(2006), 534-538.

Appaneal, R. N., Levine, B. R., Perna, F. M., \& Roh, J. L. (2009). Measuring postinjury depression among male and female competitive athletes. Journal of Sport \& Exercise Psychology, 31(1), 60-76.

Armstrong, S., \& Oomen-Early, J. (2009). Social connectedness, self-esteem, and depression symptomatology among collegiate athletes versus nonathletes. Journal of American College Health, 57(5), 521-526. doi:10.3200/ JACH.57.5.521-526

Beiter, R., Nash, R., McCrady, M., Rhoades, D., Linscomb, M., Clarahan, M., \& Sammut, S. (2015). The prevalence and correlates of depression, anxiety, and stress in a sample of college students. Journal of Affective Disorders, 17390-96. doi:10.1016/j.jad.2014.10.054

Brandy, J. M., Penckofer, S., Solari-Twadell, P. A., \& Velsor-Friedrich, B. (2015). Factors predictive of depression in first-year college students. Journal of Psychosocial Nursing and Mental Health Services, 53(2), 38-44. doi:10.3928/02793695-20150126-03

Bravata, E. A., Storch, E. A., \& Storch, J. B. (2003). Correlations Among Symptoms of Depression and Problematic Eating Patterns in Intercollegiate Athletes. Psychological Reports, 93(3,Pt2), 1243-1246. doi:10.2466/ PR0.93.8.1243-1246

Brewer, B. W. (1993). Self-identity and specific vulnerability to depressed mood. Journal of Personality, 61(3), 343364. doi:10.1111/j.1467-6494.1993.tb00284.x

"CESD-R Explanation". n. d. CESD-R The Center for Epidemiologic Studies Depression - Revised. Retrieved from < http://cesd-r.com/cesdr/>

Cohen, S., Kamarck, T., and Mermelstein, R. (1983). A global measure of perceived stress. Journal of Health and Social Behavior, 24, 386-396.

Cremades, J. G., \& Wiggins, M. S. (2008). Direction and intensity of trait anxiety as predictors of burnout among collegiate athletes. Athletic Insight: The Online Journal of Sport Psychology, 10(2).

Dishman, R. K., Hales, D. P., Pfeiffer, K. A., Felton, G. A., Saunders, R., Ward, D. S., \& ... Pate, R. R. (2006). Physical self-concept and self-esteem mediate cross-sectional relations of physical activity and sport participation with depression symptoms among adolescent girls. Health Psychology, 25(3), 396-407. doi:10.1037/02786133.25.3.396

Eaton, W. W., Smith, C., Ybarra, M., Muntaner, C., Tien, A. (2004). Center for Epidemiologic Studies Depression Scale: review and revision (CESD and CESD-R). In
ME Maruish (Ed.). The Use of Psychological Testing for Treatment Planning and Outcomes Assessment (3rd Ed.), Volume 3: Instruments for Adults, pp. 363-377. Mahwah, NJ: Lawrence Erlbaum.

Edman, J. L., Lynch, W. C., \& Yates, A. (2014). The impact of exercise performance dissatisfaction and physical exercise on symptoms of depression among college students: A gender comparison. The Journal of Psychology: Interdisciplinary and Applied, 148(1), 23-35. doi:10.1080/002 23980.2012.737871

Gerber, M., Kalak, N., Lemola, S., Clough, P. J., Perry, J. L., Pühse, U., \& ... Brand, S. (2013). Are adolescents with high mental toughness levels more resilient against stress?. Stress And Health: Journal of the International Society for the Investigation of Stress, 29(2), 164-171. doi: $10.1002 / \mathrm{smi} .2447$

Ghaedi, L., \& Kosnin, A. M. (2014). Prevalence of depression among undergraduate students: Gender and age differences. International Journal of Psychological Research, $7(2), 38-50$.

Glick, I. D., Stillman, M. A., Reardon, C. L., \& Ritvo, E. C. (2012). Managing psychiatric issues in elite athletes. Journal of Clinical Psychiatry, 73(5), 640-644. doi:10.4088/ JCP.11r07381

Goodman, F. R., Kashdan, T. B., Mallard, T. T., \& Schumann, M. (2014). A brief mindfulness and yoga intervention with an entire NCAA Division I athletic team: An initial investigation. Psychology of Consciousness: Theory, Research, and Practice, 1(4), 339-356. doi:10.1037/ cns 0000022

Hankin, B. L., \& Abramson, L. Y. (2001). Development of gender differences in depression: An elaborated cognitive vulnerability-transactional stress theory. Psychological Bulletin, 127(6), 773-796. doi:10.1037//00332909.127.6.773

Hankin, B. L., Abramson, L. Y., Moffit, T. E., Silva, P. A., McGee, M., \& Angell, K. E. (1998). Development of depression from preadolescence to young adulthood: Emerging gender differences in a 10-year longitudinal study. Journal of Abnormal Psychology, 107(1), 128-140.

Johnson, K. E., \& Taliaferro, L. A. (2011). Relationships between physical activity and depressive symptoms among middle and older adolescents: A review of the research literature. Journal for Specialists in Pediatric Nursing, 16(4), 235-251. doi:10.1111/j.1744-6155.2011.00301.x

Jones, A. L., Butryn, T. M., Furst, D. M., \& Semerjian, T. Z. (2014). A phenomenological examination of depression in female collegiate athletes. In R. Schinke, R. Schinke (Eds.)., Innovative writings in sport and exercise psychology (pp. 51-69). Hauppauge, NY, US: Nova Science Publishers.

Kimball, A., \& Freysinger, V. J. (2003). Leisure, stress, and coping: The sport participation of collegiate stu- 
dent-athletes. Leisure Sciences, 25(2-3), 115-141. doi:10.1080/01490400306569

Lavoie, J. A., \& Douglas, K. S. (2012). The Perceived Stress Scale: Evaluating configural, metric and scalar invariance across mental health status and gender. Journal Of Psychopathology And Behavioral Assessment, 34(1), 48-57. doi:10.1007/s10862-011-9266-1

Lester, D. (2014). College student stressors, depression, and suicidal ideation. Psychological Reports, 114(1), 293-296.

Lodis, C., Sigmon, S. T., Martinson, A., Craner, J., McGillicuddy, M., \& Hale, B. (2012). Is collegiate athletic participation a protective factor in seasonality?. Journal of Clinical Sport Psychology, 6(2), 113-128.

Lu, F. J., Hsu, Y., Chan, Y., Cheen, J., \& Kao, K. (2012). Assessing college student-athletes' life stress: Initial measurement development and validation. Measurement in Physical Education and Exercise Science, 16(4), 254-267. doi:10.1080/1091367X.2012.693371

Malinauskas, R. (2010). The associations among social support, stress, and life satisfaction as perceived by injured college athletes. Social Behavior and Personality, 38(6), 741-752. doi:10.2224/sbp.2010.38.6.741

Merrill, J. E., Reid, A. E., Carey, M. P., \& Carey, K. B. (2014). Gender and depression moderate response to brief motivational intervention for alcohol misuse among college students. Journal of Consulting and Clinical Psychology, 82(6), 984-992. doi:10.1037/a0037039

Miller, K. E., \& Hoffman, J. H. (2009). Mental well-being and sport-related identities in college students. Sociology of Sport Journal, 26(2), 335-356.

NCAA. (2015). Estimated probability of competing in college athletics. NCAA. Retrieved from < http://www.ncaa.org/ about/resources/research/estimated-probability-competing-college-athletics $>$

Nolen-Hoeksema, S. (2001). Gender differences in depression. Current Directions in Psychological Science, 173-176.

Petrie, T. A., Deiters, J., \& Harmison, R. J. (2014). Mental toughness, social support, and athletic identity: Moderators of the life stress-injury relationship in collegiate football players. Sport, Exercise, and Performance Psychology, 3(1), 13-27. doi:10.1037/a0032698

Radloff, L. S. (1991). The use of the Center for Epidemiologic Studies Depression Scale in adolescents and young adults. Journal of Youth and Adolescence, 20(2), 149-166.

Schaal, K., Tafflet, M., Nassif, H., Thibault, V., Pichard, C., Alcotte, M., \& ... Toussaint, J. F. (2011). Psychological balance in high level athletes: Gender-based differences and sport-specific patterns. Plos One, 6(5), 1-9. doi:10.1371/ journal.pone.0019007

Storch, E. A., Storch, J. B., Killiany, E. M., \& Roberti, J. W. (2005). Self-Reported Psychopathology in Athletes: A Comparison of Intercollegiate Student-Athletes and
Non-Athletes. Journal Of Sport Behavior, 28(1), 86-98.

Wilkins, J. A., Boland, F. J., \& Albinson, J. (1991). A comparison of male and female university athletes and nonathletes on eating disorder indices: Are athletes protected?. Journal of Sport Behavior, 14(2), 129-143.

Wilson, G., \& Pritchard, M. (2005). Comparing Sources of Stress in College Student Athletes and Non-Athletes. Athletic Insight: The Online Journal of Sport Psychology, 7(1).

Wyshak, G. (2001). Women's college physical activity and self-reports of physician-diagnosed depression and of current symptoms of psychiatric distress. Journal of Women's Health \& Gender-Based Medicine, 10(4), 363370. doi:10.1089/152460901750269689 


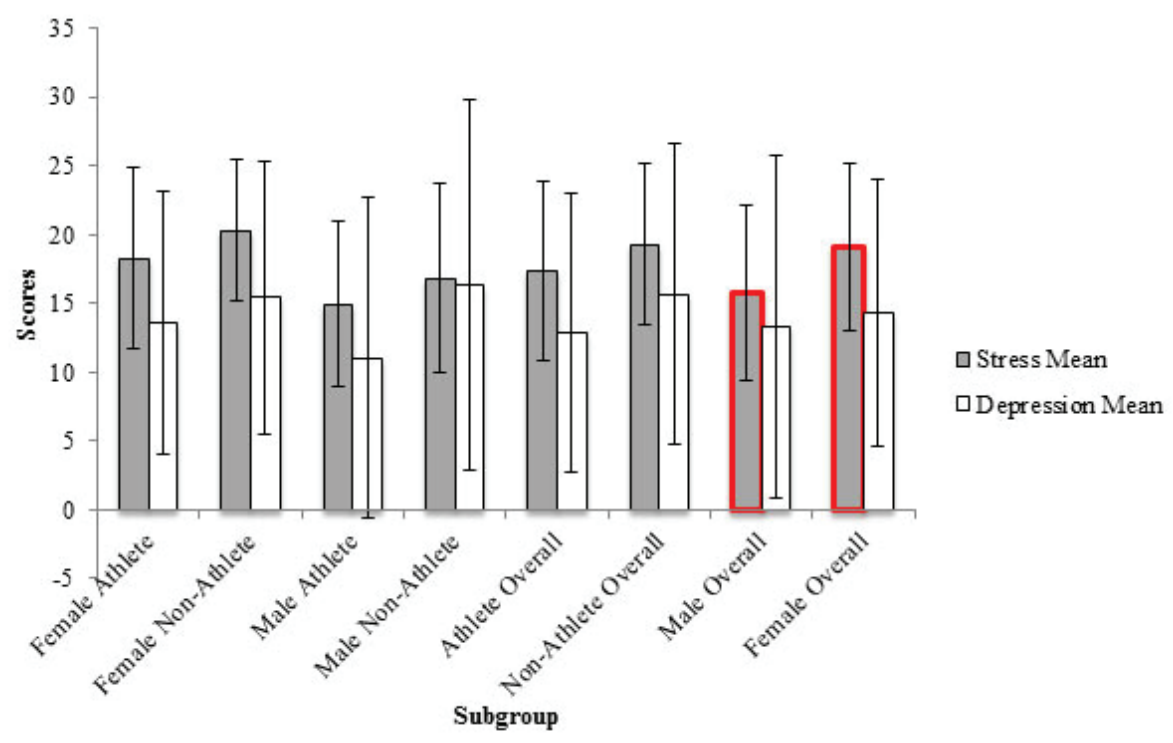

Figure 1. Means and standard deviations of stress and depression scores according to subgroup.

**Note. Male and female overall stress means were significantly different. 